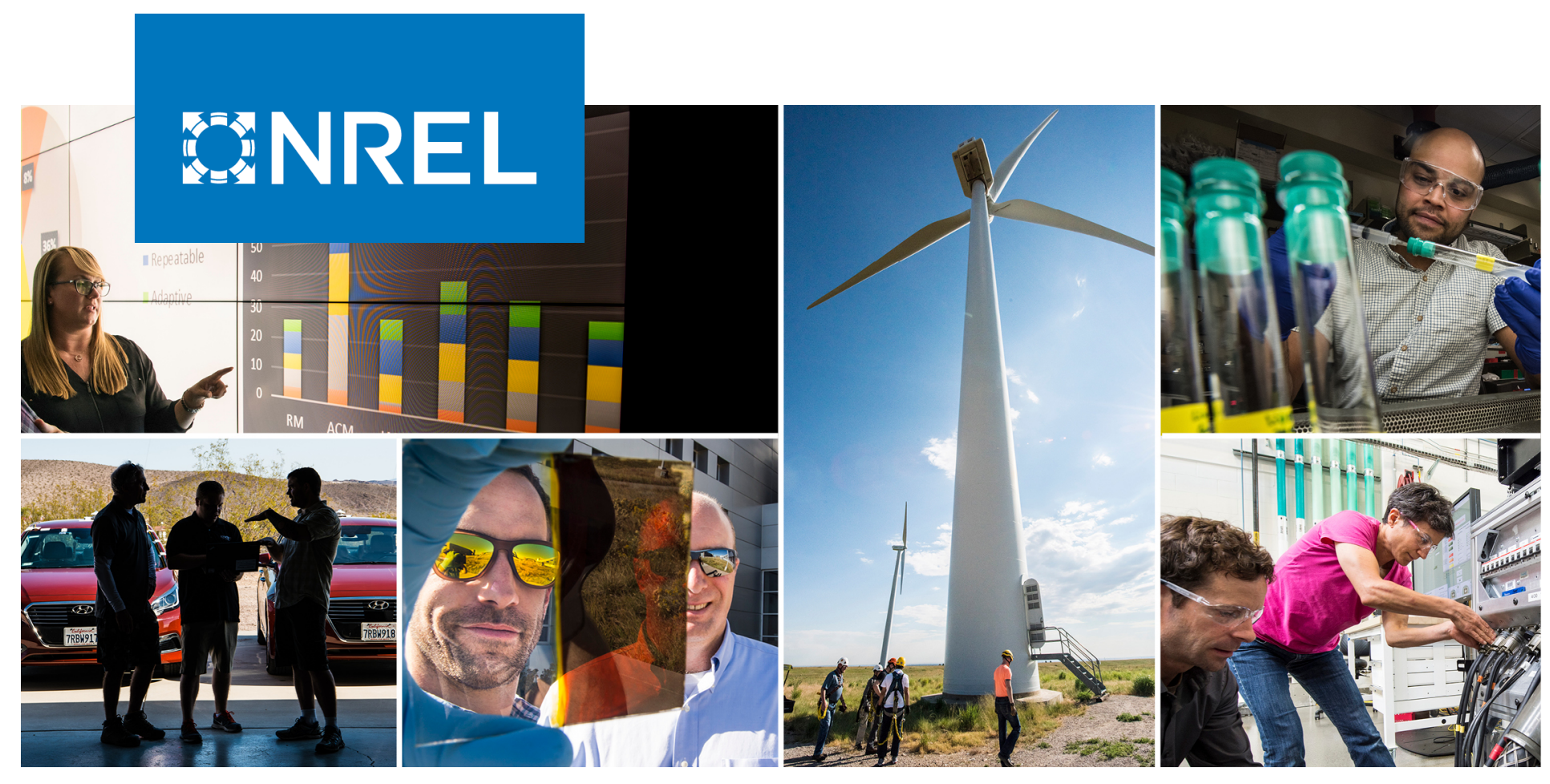

\title{
Umbilical Fatigue Analysis for a Wave Energy Converter
}

\section{Preprint}

Billy Ballard, ${ }^{1}$ Yi-Hsiang $\mathrm{Yu},{ }^{2}$ Jennifer Van Rij, ${ }^{2}$ and Frederick Driscoll ${ }^{2}$

\section{Delmar Systems}

2 National Renewable Energy Laboratory

Presented at the ASME 2020 39th International Conference on Ocean, Offshore and Arctic Engineering

August 3-7, 2020

NREL is a national laboratory of the U.S. Department of Energy

Office of Energy Efficiency \& Renewable Energy

Operated by the Alliance for Sustainable Energy, LLC

This report is available at no cost from the National Renewable Energy Laboratory (NREL) at www.nrel.gov/publications.

\section{Conference Paper}

NREL/CP-5000-76015

September 2020 


\title{
GHREL
}

\section{Umbilical Fatigue Analysis for a Wave Energy Converter}

\section{Preprint}

\author{
Billy Ballard, ${ }^{1} \mathrm{Yi}-\mathrm{H}$ siang $\mathrm{Yu},{ }^{2}$ Jennifer Van Rij, ${ }^{2}$ and \\ Frederick Driscoll ${ }^{2}$
}

1 Delmar Systems

2 National Renewable Energy Laboratory

\section{Suggested Citation}

Ballard, Billy, Yi-Hsiang Yu, Jennifer Van Rij, and Frederick Driscoll. 2020. Umbilical Fatigue Analysis for a Wave Energy Converter: Preprint. Golden, CO: National

Renewable Energy Laboratory. NREL/CP-5000-76015.

https://www.nrel.gov/docs/fy20osti/76015.pdf.

NREL is a national laboratory of the U.S. Department of Energy Office of Energy Efficiency \& Renewable Energy Operated by the Alliance for Sustainable Energy, LLC

This report is available at no cost from the National Renewable Energy Laboratory (NREL) at www.nrel.gov/publications.

Contract No. DE-AC36-08GO28308
Conference Paper

NREL/CP-5000-76015

September 2020

National Renewable Energy Laboratory 15013 Denver West Parkway Golden, CO 80401

303-275-3000 • www.nrel.gov 


\section{NOTICE}

This work was authored in part by the National Renewable Energy Laboratory, operated by Alliance for Sustainable Energy, LLC, for the U.S. Department of Energy (DOE) under Contract No. DE-AC36-08GO28308. Funding provided by U.S. Department of Energy Office of Energy Efficiency and Renewable Energy Water Power Technologies Office. The views expressed herein do not necessarily represent the views of the DOE or the U.S. Government. The U.S. Government retains and the publisher, by accepting the article for publication, acknowledges that the U.S. Government retains a nonexclusive, paid-up, irrevocable, worldwide license to publish or reproduce the published form of this work, or allow others to do so, for U.S. Government purposes.

This report is available at no cost from the National Renewable Energy Laboratory (NREL) at www.nrel.gov/publications.

U.S. Department of Energy (DOE) reports produced after 1991 and a growing number of pre-1991 documents are available free via www.OSTI.gov.

Cover Photos by Dennis Schroeder: (clockwise, left to right) NREL 51934, NREL 45897, NREL 42160, NREL 45891, NREL 48097, NREL 46526.

NREL prints on paper that contains recycled content. 


\section{UMBILICAL FATIGUE ANALYSIS FOR A WAVE ENERGY CONVERTER}

\author{
Billy Ballard \\ Delmar Systems \\ Houston TX, USA \\ Email: Billy.Ballard@delmarsystems.com \\ Jennifer Van Rij \\ National Renewable Energy Laboratory \\ Golden, CO, USA \\ Email: jennifer.vanrij@nrel.gov
}

\author{
Yi-Hsiang Yu* \\ National Renewable Energy Laboratory \\ Golden, CO, USA \\ Email: yi-hsiang.yu@nrel.gov \\ Frederick Driscoll \\ National Renewable Energy Laboratory \\ Golden, CO, USA \\ Email: Frederick.Driscoll@nrel.gov
}

\begin{abstract}
Unique umbilical designs for wave energy converters (WECs), including the ability to handle significantly larger motions and loads over long deployments, are often required when conventional marine umbilical designs for offshore oil and gas and offshore wind may not meet the design and cost needs of wave energy technologies. This study details a fatigue analysis of a dynamic power umbilical attached to a two-body floating point absorber WEC system, using the sea states provided for the PacWave testing facilities. The 6 degrees of freedom motion time history for the WEC was simulated, and the motions of the attachment point for the umbilical on the WEC and respective sea states were used to analyze the dynamic motions and fatigue of the connected power umbilical to predict the fatigue life. The results show that the fatigue damage observed is more significant in shallow water, and extensive fatigue damage may occur because of the larger curvature response of the umbilical. The umbilical configurations departing at $90 \mathrm{deg}$ off incoming waves were found to have the highest fatigue life attributed to less extension or compression of the umbilical. However, additional bend stiffener/limiter features may need to be incorporated into the buoyancy section and touchdown regions to minimize curvature-induced fatigue.
\end{abstract}

\section{KEYWORDS}

Wave energy converter; umbilical; fatigue analysis

\section{NOMENCLATURE}

$\mathrm{A}_{\infty} \quad$ Added mass matrix at infinite frequency

$\mathrm{X}$ Translational and rotational displacement vector

M Mass matrix

K Matrix of impulse response function

$\mathrm{F}_{\text {ext }} \quad$ Wave-excitation force vector

$\mathrm{F}_{\mathrm{MD}} \quad$ Mean drift force vector

FPTO Power-take-off force vector

$\mathrm{F}_{\mathrm{mo}} \quad$ Mooring force vector

$F_{\text {vis }} \quad$ Quadratic viscous force vector

$F_{\text {res }} \quad$ Net buoyancy restoring force

$T_{D} \quad$ Design tension

$R_{D} \quad$ Design radius curvature

$E l_{s} \quad$ Bend stiffness along the bend stiffener

$E l_{r} \quad$ Bend stiffness of the umbilical

\section{INTRODUCTION}

The umbilical is an essential part of the overall design for a wave energy converter (WEC). Conventional marine umbilical designs for offshore oil and gas and offshore wind are often applied (e.g., [1]). However, it may not meet the design and cost needs of wave energy technologies, where unique requirements for WEC designs, including the ability to handle significantly larger motions and loads over long deployment duration, are often needed. As a result, poorly designed umbilical cables can fail

${ }^{*}$ Address all correspondence to this author. 
early and/or increase project costs. Premature umbilical failure can be catastrophic because umbilical cables are in the critical path to delivering power and are difficult and expensive to swap out. To our knowledge, no umbilical product line exists that is specifically designed or able to meet the operational, functional, and cost requirements of being connected to a WEC. The design of robust and cost-effective umbilical cables for WECs requires accurate estimates of motions, loads, vibration, bending, pressure, abrasion, fatigue, failure modes, corrosion, heating, resistance, dielectric strength, and possibly more factors, which may be experienced by a range of expected WEC device types under extreme and regular operating conditions, over the lifetime of the project.

The design and utilization of robust and cost-effective medium-voltage power and communication umbilicals that connect WECs to subsea transmission lines are essential for the success of the development of WEC technology and for the reduction of levelized cost of energy for commercial wave energy systems. This study details a fatigue analysis of a dynamic power umbilical attached to a two-body floating point absorber (FPA) type of WECs system using sea states for the PacWave testing facilities. The 6 degrees of freedom motion time history for the WEC was obtained through the use of WEC-Sim [2]. The motions of the attachment point for the umbilical on the WEC and respective sea states were used to analyze the dynamic motions and fatigue of the connected power umbilical. The cable dynamic simulations were carried out using OrcaFlex [3]. In the paper, the methodology of the two numerical models is briefly reviewed, followed by the approach to determine the size of the bend stiffener. Finally, the results of the fatigue life analysis on a lazy wave umbilical configuration with and without the consideration of mean drift force and for water depths of $50 \mathrm{~m}$ and 100 $\mathrm{m}$ are presented.

\section{METHODOLOGY}

A summary of the site location and wave environment, numerical methods, device and cable properties, bend stiffener sizing, and fatigue analysis are described in this section.

\section{Site Location and Wave Environment}

This analysis used the wave scatter diagram (Table 1) to represent the joint probability distribution of significant wave height and energy period described for the PacWave test site. PacWave is formerly known as the Pacific Marine Energy Center South Energy Test Site (Fig. 1), which is located in the Pacific Northwest region near the city of Newport, Oregon, and Yaquina Bay. PacWave is a grid-connected testing facility for WECs, funded by the U.S. Department of Energy, which is expected to begin operation in 2021 [4].

The joint probability distribution of the sea states over an annual year for the PacWave location [5] was used to develop the case matrix for analyzing the umbilical, as shown in 1 . The wave scatter table provided includes sea states ranging from 0.5
TABLE 1. WAVE SCATTER DIAGRAM FOR PACWAVE
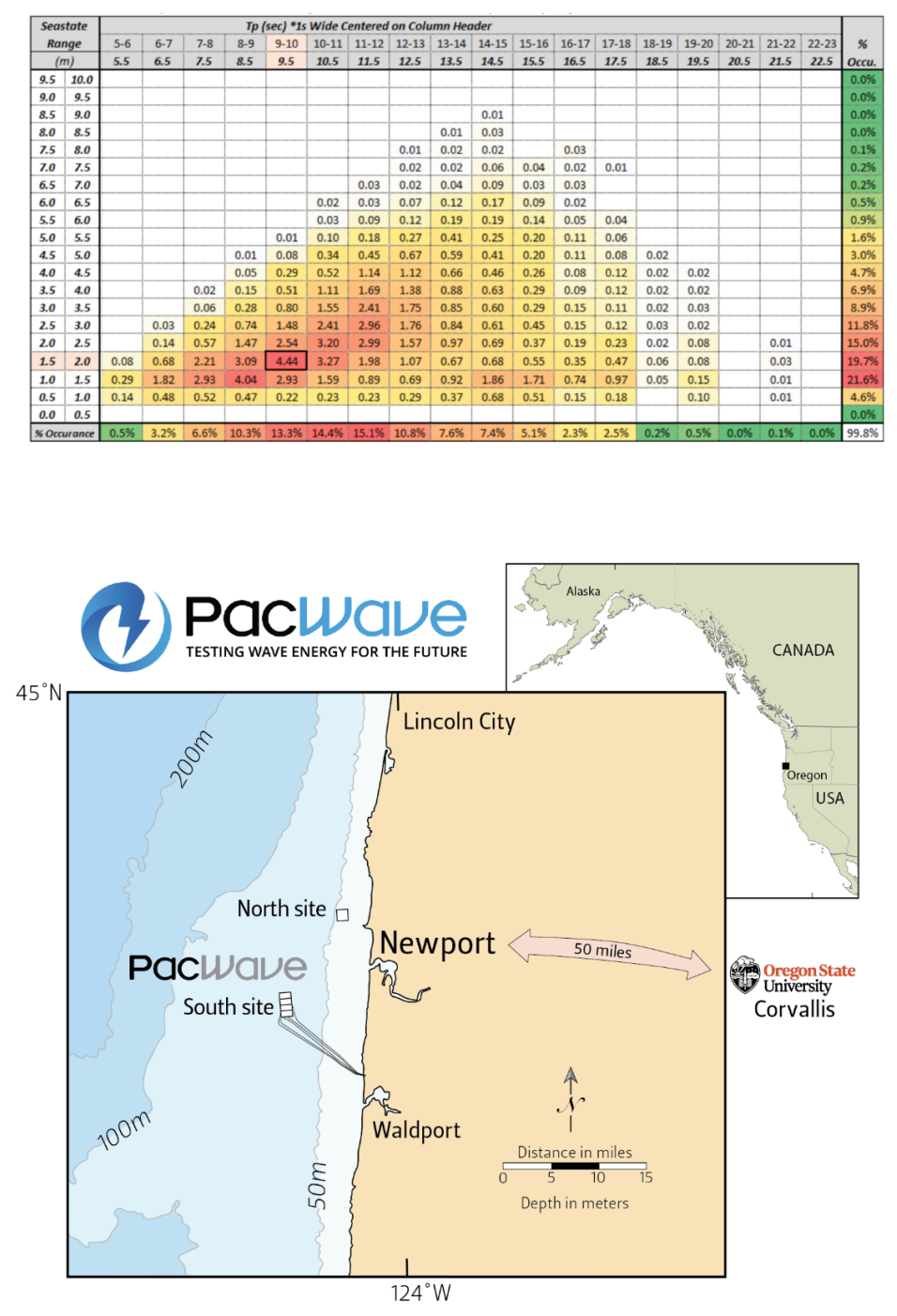

FIGURE 1. PACWAVE TEST SITE LOCATION

$\mathrm{m}$ to $9.0 \mathrm{~m}$, with corresponding peak spectral periods from $5.0 \mathrm{~s}$ to $22.0 \mathrm{~s}$. The PacWave data show that the most frequently occurring sea state is within the range of $1.5 \mathrm{~m}$ to $2.0 \mathrm{~m}$, with peak energy periods of $9.0 \mathrm{~s}$ to $10.0 \mathrm{~s}$. The total occurrence for each wave frequency and for each significant wave height are shown at the bottom and to the right of the table, respectively, depicting the majority of sea states ranging from $0.5 \mathrm{~m}$ to $3.5 \mathrm{~m}$ and peak periods ranging from $8.0 \mathrm{~s}$ to $13.0 \mathrm{~s}$. The frequencies of occurrence of less than $0.01 \%$ were considered negligible and were not shown in Table 1. However, it should be noted that extreme sea states with very low probabilities of occurrence can result in very large fatigue damage (low cycle fatigue), should they occur while deployed. As such, in practice it is recommended to conservatively account for the low-probability events in the fatigue assessment.

As shown in Fig. 2, the waves for the PacWave location predominantly come from the west toward the shore, and one environmental heading was used throughout all analyses. To account 


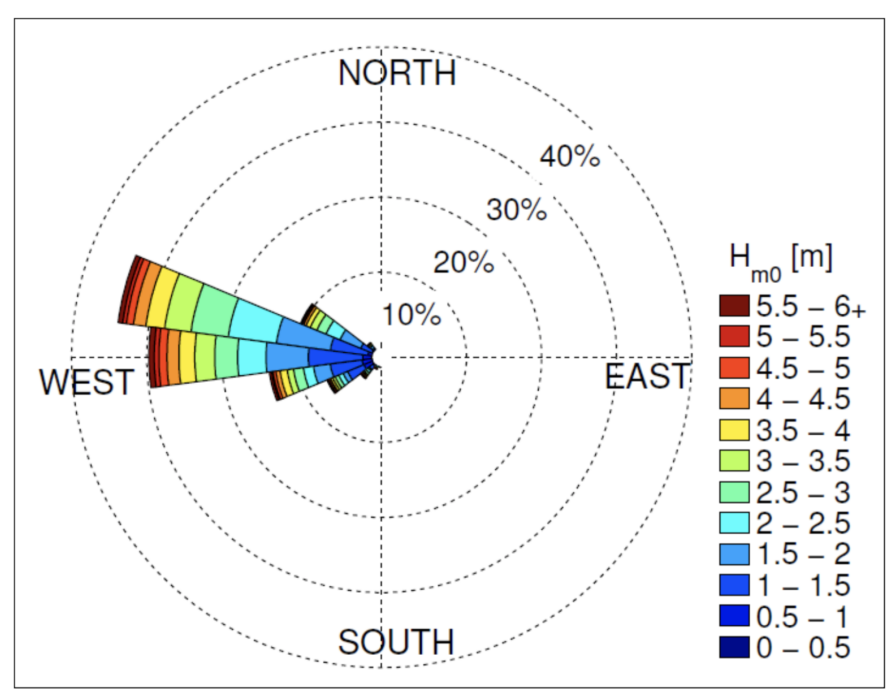

FIGURE 2. ANNUAL WAVE ROSE OF SIGNIFICANT WAVE HEIGHT AND DIRECTION

for different umbilical install azimuths, five line azimuths were analyzed every $45 \mathrm{deg}$ from $0 \mathrm{deg}$ (west, into the environment) to $180 \mathrm{deg}$ (east, away from the environment).

\section{Hydrodynamics Modeling}

To estimate loads and fatigue damage for WEC umbilical cables, the dynamic response of the two-body FPA (Fig. 3) was obtained using WEC-Sim. [2]. WEC-Sim is a radiation-anddiffraction-method-based numerical model that has been developed to solve the system dynamics of WECs comprising multiple bodies, joints, power-take-off systems, and mooring systems [6]. The dynamic response in WEC-Sim is calculated by solving the equation of motion in the time domain for each body about its center of gravity, based on Cummins' equation [7],

$$
\begin{aligned}
\left(\mathrm{M}+\mathrm{A}_{\infty}\right) \ddot{\mathrm{X}}= & -\int_{0}^{t} \mathrm{~K}(t-\tau) \dot{\mathrm{X}}(\tau) d \tau \\
& +\mathrm{F}_{\mathrm{ext}}+\mathrm{F}_{\mathrm{vis}}+\mathrm{F}_{\mathrm{res}}+\mathrm{F}_{\mathrm{PTO}}+\mathrm{F}_{\mathrm{mo}}+\mathrm{F}_{\mathrm{MD}}
\end{aligned}
$$

In this study, we used WAMIT [8], which is a boundary-elementmethod-based frequency-domain potential flow solver, to obtain the added mass, wave excitation, impulse response function, and restoring stiffness terms. To account for the influence of the drift on the cable loading, the calculation of the mean drift force and moment was also included, based on the momentum conservation principle.

The dimensions and mass properties for the WEC are presented in Fig. 3 and Table 2, respectively. The mass for each body was equal to its displaced mass, and both the float and spar/plate were located at their equilibrium positions. The PacWave site has water depths ranging from $58 \mathrm{~m}$ to $75 \mathrm{~m}$ [5]. Therefore, the simulations were carried out in two water depths of $50 \mathrm{~m}$ and $100 \mathrm{~m}$ in this study to account for the water depth

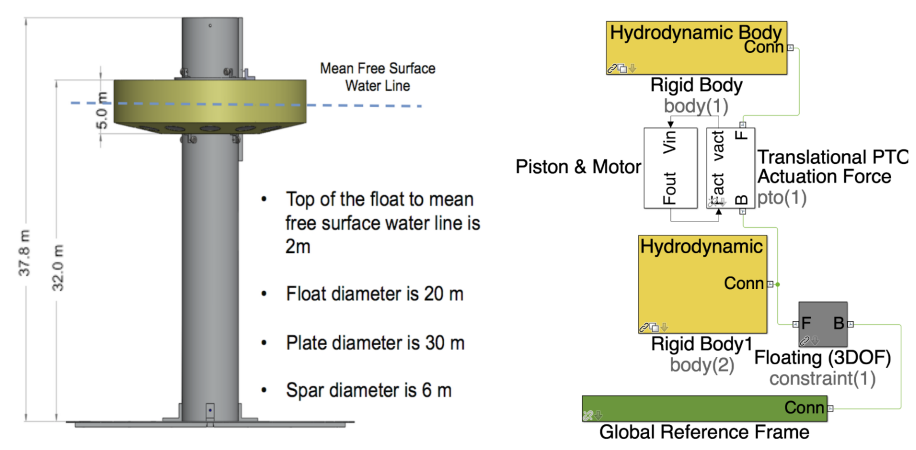

FIGURE 3. THE SCHEMATIC (SIDE VIEW) OF THE FPA DESIGN (LEFT) AND THE WEC-SIM MODEL (RIGHT)

TABLE 2. TWO-BODY FLOATING POINT ABSORBER WEC MODEL SPECIFICATIONS

\begin{tabular}{llllll}
\hline & $\begin{array}{l}\text { Center of } \\
\text { Gravity }(\mathrm{m})\end{array}$ & $\begin{array}{l}\text { Mass } \\
\left(10^{3} \mathrm{~kg}\right)\end{array}$ & \multicolumn{3}{c}{$\begin{array}{c}\text { Moment of Inertia } \\
\left(10^{3} \mathrm{~kg}-\mathrm{m}^{2}\right)\end{array}$} \\
\hline \multirow{2}{*}{ Float } & {$[0,0,-0.72]$} & 727.01 & 0 & 21,300 & 4.30 \\
& & & 0 & 4.30 & 31,700 \\
\hline Spar/ & & & 137,000 & 0 & 0 \\
Plate & {$[0,0,-21.29]$} & 878.30 & 0 & 137,000 & 218 \\
& & & 0 & 218 & 28,500 \\
\hline
\end{tabular}

variation. The WEC was connected to three mooring chains, and WEC-Sim was coupled with MoorDyn [9] for simulating the mooring dynamics. To represent the effect of viscosity, a quadratic damping coefficient of 1 was used in surge for both the float and the spar/plate. For heave and pitch, the values were set to 1.1 and 3.7 for the float and spar/plate, respectively.

The WEC-Sim simulations were carried out based on the joint probability distribution of the sea states given in Table 1, with passive damping tuned to maximize the power output for each sea state. The time history of the attachment point of the umbilical and the WEC was recorded in WEC-Sim, with and without the influence of mean drift force on the device, to analyze the layout and dynamic load effect of the umbilical cables.

Note that, based on the given water depth in the case studies, the WEC is operated in intermediate depth and deep water. For simplicity, a deep-water assumption was made for the analysis. Since the study is focusing on the fatigue analysis of the umbilical design, we assumed WEC-Sim and OrcaFlex model is one-way coupled and the influence of the umbilical cable dynamics on the WEC response is negligible, which can be overly simplified for practical applications. However, the modeling of fully coupled interaction between the WEC and the umbilical is beyond the scope of this study. Nevertheless, a model to include the bending stiffness calculation is currently being developed in moorDyn and will be fully coupled to WEC-Sim for a more detailed study in the future. 


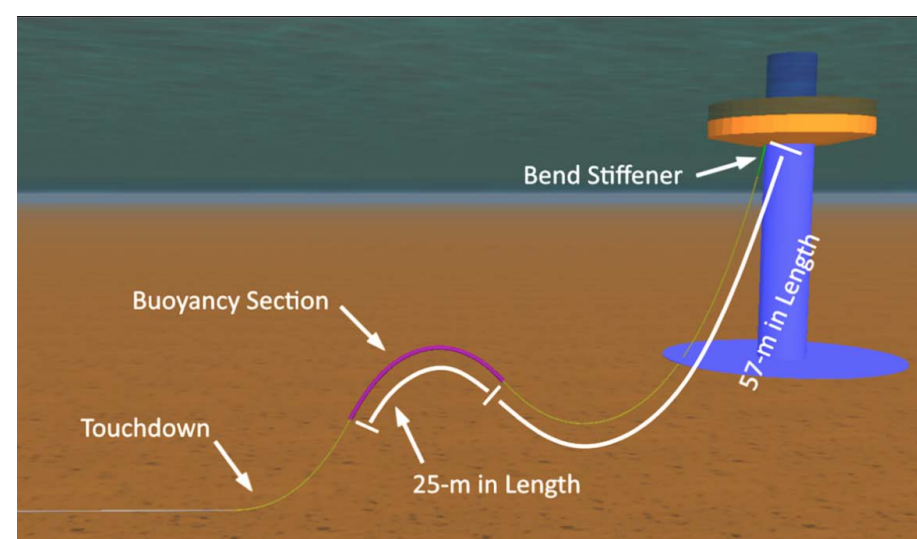

FIGURE 4. THE ORCAFLEX MODEL (50-M WATER DEPTH)

\section{Cable Dynamics Modeling}

The dynamic motions and fatigue of the connected power umbilical were simulated using a commercial offshore dynamic analysis and marine system modeling tool (OrcaFlex) [3]. This analysis used the exact same sea states simulated in WEC-Sim. The fatigue analysis is performed on a lazy wave umbilical configuration, as shown in Fig. 4, with the surface float of the WEC as solid orange and the remaining vertical column with the reaction plate in blue.

For the 50-m water depth case, the total length of the umbilical used is $137 \mathrm{~m}$ from the WEC connection to the seabed connection past the touchdown location. This includes additional length of the umbilical to sufficiently reduce the impact of the anchored location, and the first $4 \mathrm{~m}$ of the umbilical is inside the bend stiffener. It also has a $25-\mathrm{m}$ buoyancy section, which is $57 \mathrm{~m}$ from the WEC connection. The umbilical modeled has an average pretension of $2.4 \mathrm{mT}$ with a mean hang-off angle of $11.8 \mathrm{deg}$. For the $100-\mathrm{m}$ water depth case, the length is $310 \mathrm{~m}$, with a 42-m buoyancy section that is $108 \mathrm{~m}$ from the WEC connection. The umbilical modeled has an average pretension of $4.7 \mathrm{mT}$ with a mean hang-off angle of $10.0 \mathrm{deg}$. For simplicity, the connection point of the umbilical is assumed to be attached to the vertical column, such that the surface float does not clash with the umbilical at the maximum range-of-surface float motion. The umbilical catenary assumes the reaction plate of the WEC is designed to provide sufficient clearance.

\section{Bend Stiffener Sizing}

A bend stiffener limits the stresses in the umbilical during the dynamic motions of the WEC. The bend stiffener gradually increases the bending stiffness of the umbilical to a significantly larger value that can be rigidly connected to the WEC. The preliminary bend stiffener used in the analysis followed the study presented in [10]. To develop the preliminary bend stiffener, each bin was first run without a bend stiffener, with the umbilical pinned at the connection location on the WEC. From each bin, the maximum and minimum line tensions with the maximum magnitude of declination or azimuth were used to determine the sizing of the bend stiffener.

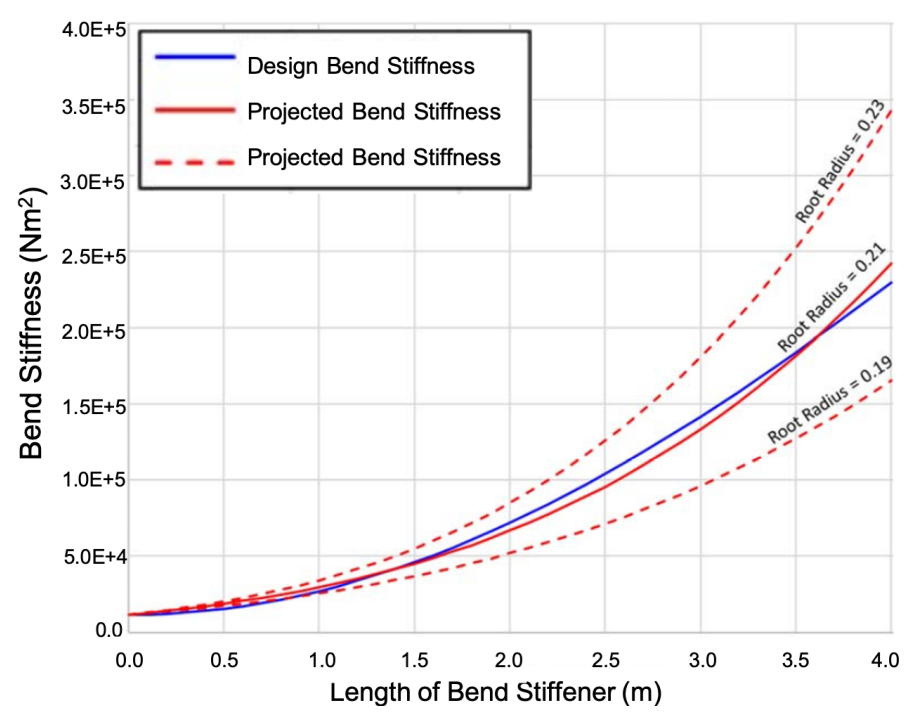

FIGURE 5. BEND STIFFNESS DESIGN

The design tension, $T_{D}$, and design radius curvature, $R_{D}$, are based on nondimensional values referenced from the nondimensional bend stiffener design curves [10]. These values are then used to determine the bend stiffness along the bend stiffener. The shortest length of the bend stiffener is about $4 \mathrm{~m}$, based on the minimum bend radius.

$$
E l_{s}=E l_{r}+2 T_{D} R_{D}^{2} \operatorname{Sin}^{2}\left(\frac{s}{2 R_{D}}\right), 0 \leq s \leq R_{D} \alpha_{R}
$$

Figure 5 shows the bend stiffness along the length of the bend stiffener. The blue line represents the bend stiffness, as described in Eq. 2, using the design tension and radius curvature. The red lines indicate the bend stiffness using the varied root radius. The solid red line shows the root radius of $0.21 \mathrm{~m}$ was used in the analysis.

\section{Fatigue Analysis}

The fatigue life of the umbilical was calculated using the fatigue analysis module within OrcaFlex. The module uses a cycle-counting technique to break down each random wave case into a series of half cycles, and then sums the damage. This damage value for each load case is then scaled, based on the specified total exposure time and summed to give the overall total damage. The exposure time is determined by the frequency of occurrence for each bin, as shown in Table 1. The conductors in the umbilical are designed to meet the requirements set by International Organization for Standardization standard [1]. It is assumed that the individual elements within the umbilical move freely in longitudinal direction against each other, but there is no relative movement between the strands within the conductors.

The stresses associated with the cyclic tensile and bending loads are determined for each of the simulated environmental bins, for 16 evenly spaced intervals around the umbilical circumference. Using the rain flow counting method, the number of half 


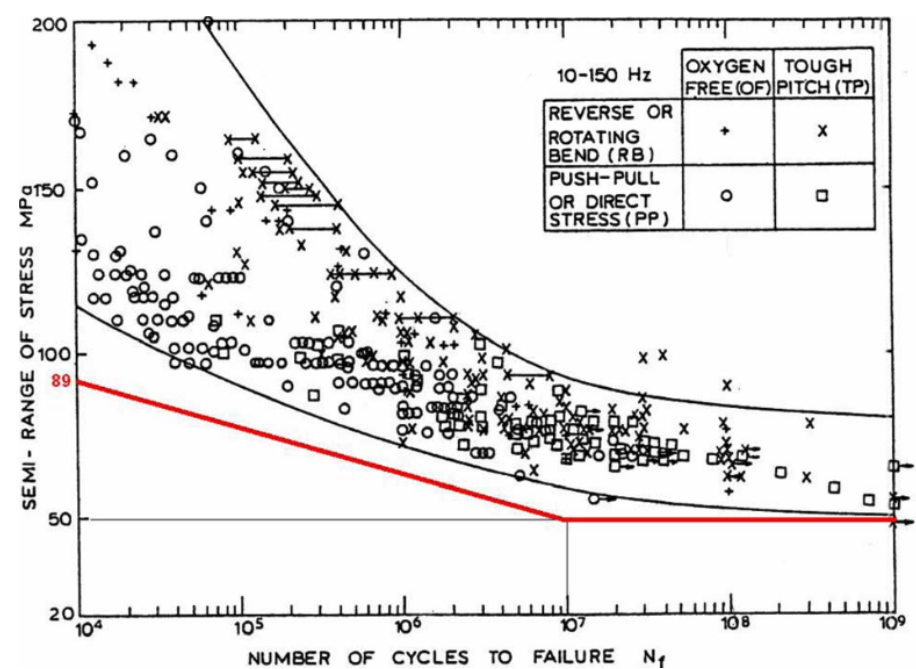

FIGURE 6. S-N CURVE FOR THE HIGH-VOLTAGE COPPER CONDUCTORS

cycles occurring in each simulation run were determined. The S$\mathrm{N}$ curve, shown in Fig. 6, was used to calculate the resulting damage caused by each half cycle. The proposed $\mathrm{S}-\mathrm{N}$ curve was defined for stress amplitudes above $50 \mathrm{MPa}$, following Murphy's suggestion [11]. The Palmgren-Miner rule was used to sum the damage caused by each of the half cycles to determine the damage value for the load case. The \% occurrence from the wave scatter diagram was incorporated via the exposure time factors, with the scaled result reflective of the total overall annual damage to the umbilical. Overall, the fatigue life is inversely proportional to the total annual damage.

\section{RESULTS}

The analysis of the fatigue life for the umbilical of the WEC system is presented in this section, including the influence of the mean drift force and moment, bend stiffener, and water depth.

\section{Fatigue Life Analysis}

Figure 7 plots fatigue results for the bend stiffener and buoyancy sections of the umbilical, with and without considering the mean wave drift force for the case of 50-m water depth. As shown in the figure, most of the fatigue damage occurs in the buoyancy section for the 0-deg azimuth with a 0.07-year (25 days) fatigue life. This is because the WEC surges back and forth, which results in a pinching motion along the buoyancy section. The second most damage-producing section is located at the touchdown point for the 180-deg azimuth with a 0.39 -year (142 days) fatigue life. The least damage produced occurs with the 90-deg azimuth with a 461-year fatigue life, which assumes the umbilical at the touchdown is allowed to move freely along the seabed without trenching. Additional abrasion protection at the touchdown is also recommended because of the resulting motions and clashing that will be present with the sandy bottom. The results also show that not accounting for mean wave drift

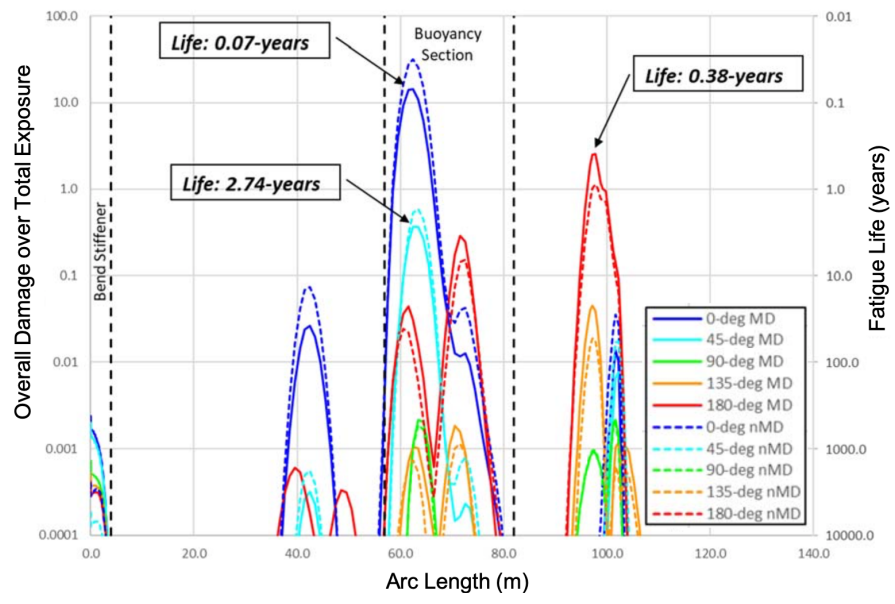

FIGURE 7. FATIGUE RESULTS COMPARISON WITH AND WITHOUT ACCOUNTING FOR MEAN DRIFT FORCE

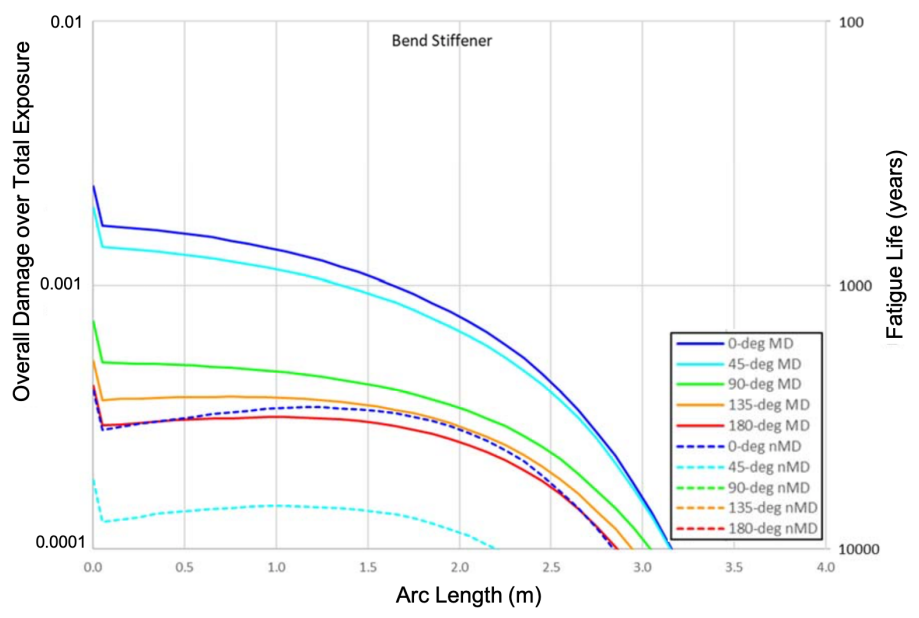

FIGURE 8. BEND STIFFENER SECTION FATIGUE RESULTS COMPARISON WITH ACCOUNTING MEAN WAVE DRIFT

when simulating the WEC system could underestimate the fatigue life in some cases (e.g., the 0-deg and 45-deg umbilical azimuths).

Figure 8 plots the fatigue results for the bend stiffener section from the previously shown fatigue results found in Figure 7. Overall, the accounting for the mean wave drift produces a reduced fatigue life in the section, and the umbilical sustains an extreme amount of fatigue damage for all installation azimuths without a bend stiffener.

\section{Influence of Water Depth}

Figure 9 shows the curvature time history of the node showing the peak curvature at the sea state of $8.25 \mathrm{~m}$ with a peak period of $14.5 \mathrm{~s}$ for both the $50-\mathrm{m}$ and $100-\mathrm{m}$ water depth configurations. The red dashed line depicts the umbilicals minimum bend radius of $2.64 \mathrm{~m}$, and the umbilical configuration in the $100-\mathrm{m}$ water depth shows minimal fatigue damage. 


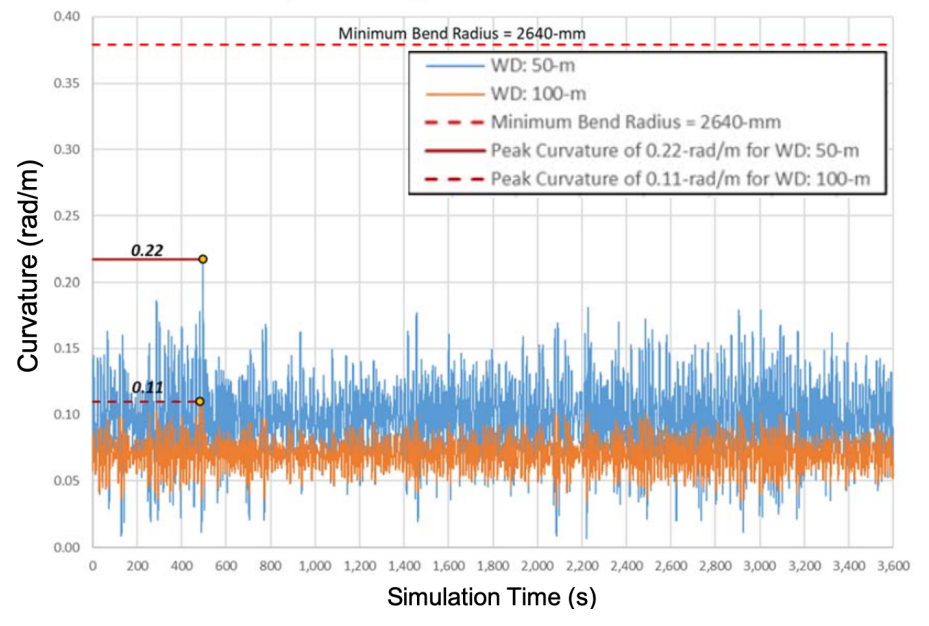

FIGURE 9. CURVATURE TIME HISTORY AT NODEPRODUCING PEAK CURVATURE

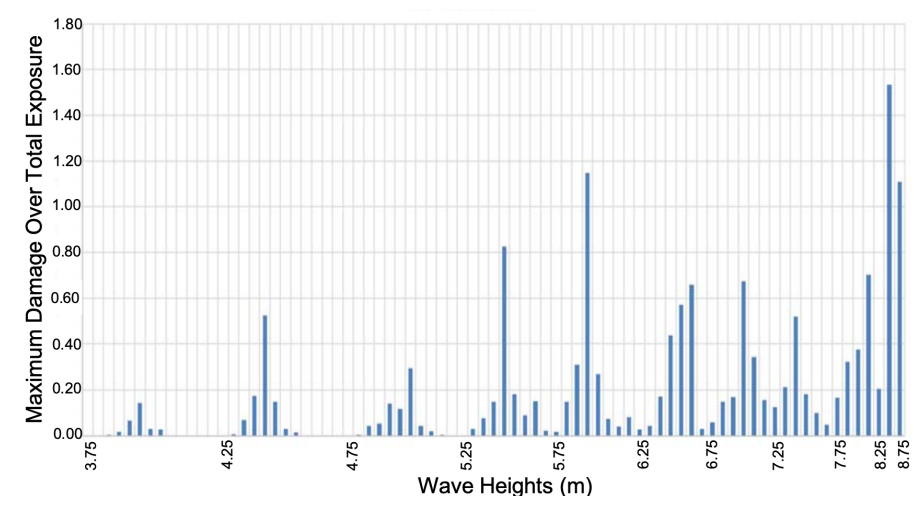

FIGURE 10. MAXIMUM DAMAGE OVER EXPOSURE AT INDIVIDUAL ARC POINTS (WATER DEPTH OF $50 \mathrm{M}$ )

\section{Umbilical Configuration Sensitivity}

The fatigue results of the umbilical configuration for the 50$\mathrm{m}$ water depth showed a fatigue life of 0.07 years in the 0 -deg azimuth. A sensitivity of varying the length of the buoyancy section and the length of the top section of the umbilical was performed. The sea state load case that contributed the most to the overall damage was selected. Figure 10 shows the maximum damage scaled with the associated exposure, as determined from the sea states, $3.75 \mathrm{~m}$ to $8.75 \mathrm{~m}$. The majority of the damage is accumulated from the sea state of $8.25 \mathrm{~m}$ with a peak period of $14.5 \mathrm{~s}$.

The case was then used to perform a sensitivity on the umbilical length and the buoyancy section length. Figure 11 shows the sensitivity fatigue results with the combined section (buoyancy with topside umbilical) lengths. As shown in the figure, reducing the length of the buoyancy section and topside section from $13.7 \mathrm{~m}$ ft to $12.5 \mathrm{~m}$ reduced the fatigue damage for this case from 1.60 to 0.71 . This could potentially reduce the other cases by $56 \%$, improving the fatigue life of the umbilical.

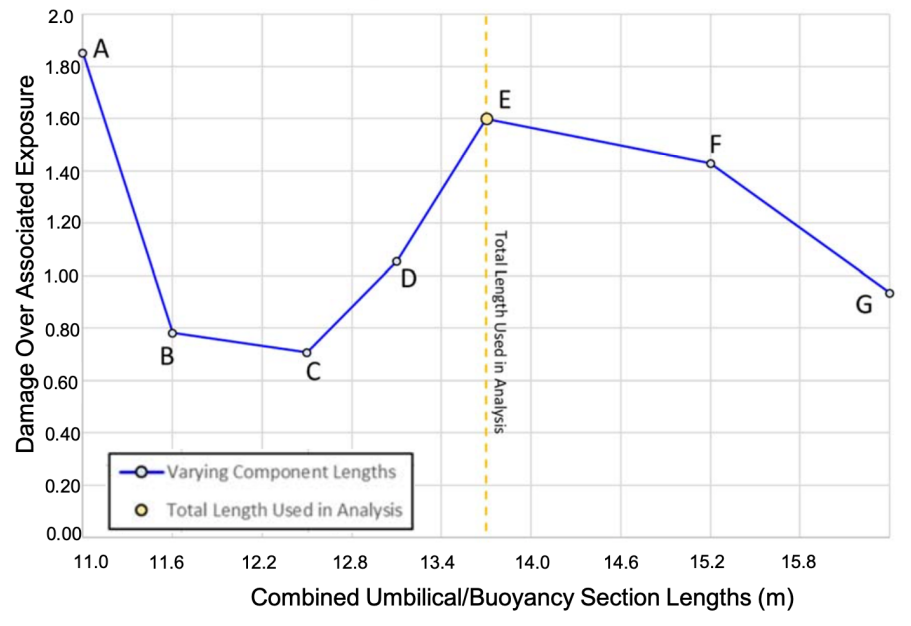

FIGURE 11. DAMAGE SENSITIVITY OVER ASSOCIATED EXPOSURE FOR VARYING SECTION LENGTHS

\section{CONCLUSIONS}

The fatigue life for a dynamic power umbilical attached to a two-body floating WEC device was analyzed, including the influence of the mean drift force and moment, bend stiffener, and water depth. WEC-Sim simulations were carried out using WEC-Sim to obtain the dynamic motion of the device. These motions and respective sea states were used to analyze the dynamic motions and fatigue of the connected power umbilical using OrcaFlex. The results show that the fatigue damage observed is more significant in the 50-m water depth than the $100-\mathrm{m}$ water depth. For the 100-m water depth umbilical configuration, minimal fatigue damage for all line azimuths was observed once a bend stiffener was incorporated. For the 50-m water depth umbilical configuration, extensive fatigue damage was observed, because of the larger curvature response of the umbilical. The umbilical configurations departing at 90 deg off incoming waves were found to have the highest fatigue life attributed to less extension or compression of the lazy wave (assuming the umbilical cable does not trench and has adequate cladding to prevent wear). However, additional bend stiffener/limiter features may be required to be incorporated into the buoyancy section and touchdown regions to minimize curvature-induced fatigue. It was also found that incorporation of a bend stiffener at the connection of the umbilical cable to the WEC is essential to limiting bending strain in this region for the given water depths. Finally, a lazy $\mathrm{S}$ arrangement tuned for the device response envelope and sitespecific water depth is key to increasing compliance to prevent snap loading and reduce the resulting extreme bending fatigue in the touchdown region.

For future work, a preliminary bend stiffener was determined for use in the analysis to estimate fatigue damage at the connection point on the WEC. This bend stiffener was developed using the recommendations of the bend stiffener design standard for umbilicals. This could be further expanded upon to incorporate actual bend stiffener manufacturer data into the design. For 
this analysis, the WEC motions in the 100-m water depth were very similar to the 50-m water depth motions. Depending on the mooring system design, the 100-m water depth WEC motions may see greater surge extremes that could potentially decrease the fatigue life, increasing the fatigue damage caused by the decreased stiffness of the associated mooring system. Finally, the same umbilical configuration was used for all azimuths analyzed. A sensitivity was performed on the 0-deg azimuth, showing that reducing the buoyancy section and the umbilical section may increase the fatigue life, decreasing the fatigue damage. This may lead to different umbilical configurations, depending on line installation headings based on the incoming waves.

\section{ACKNOWLEDGMENT}

This work was authored [in part] by the National Renewable Energy Laboratory, operated by Alliance for Sustainable Energy, LLC, for the U.S. Department of Energy (DOE) under Contract No. DE-AC36-08GO28308. Funding provided by the U.S. Department of Energy Office of Energy Efficiency and Renewable Energy Water Power Technologies Office. The views expressed in the article do not necessarily represent the views of the DOE or the U.S. Government. The U.S. Government retains and the publisher, by accepting the article for publication, acknowledges that the U.S. Government retains a nonexclusive, paid-up, irrevocable, worldwide license to publish or reproduce the published form of this work, or allow others to do so, for U.S. Government purposes.

\section{REFERENCES}

[1] British Standard, 2009. Petroleum and Natural Gas In- dusties Design and Operation of Subsea Production System Part 5: Subsea Umbilicals, International Standard. Tech. rep.

[2] WEC-Sim (Wave Energy Converter SIMulator).

[3] OrcaFlex, 2015. OrcaFlex Manual. Orcina Ltd., Daltongate Ulverston Cumbria, UK.

[4] PacWave Test Site.

[5] Dallman, A. R., and Neary, V. S., 2014. Characterization of U.S. Wave Energy Converter (WEC) Test Sites: A Catalogue of Met-Ocean Data. Tech. Rep. September, Sandia National Laboratories, Albuquerque, NM.

[6] Yu, Y.-H., Lawson, M., Ruehl, K., and Michelen, C., 2014. "Development and Demonstration of the WEC-Sim Wave Energy Converter Simulation Tool". In 2nd Marine Energy Technology Symposium.

[7] Cummins, W., 1962. The Impulse Response Function and Ship Motions. Tech. rep., David Taylor Model Dasin (DTNSRDC).

[8] Lee, C., and Newman, J., 2015. WAMIT User Manual Version 7.1. Chestnut Hill, MA, USA.

[9] Hall, M., 2015. MoorDyn User's Guide.

[10] Sodahl, N., and Ottesen, T., 2011. "Bend stiffener design for umbilicals". pp. 449-460.

[11] Murphy, M. C., 1981. "The engineering fatigue properties of wrought copper". Fatigue \& Fracture of Engineering Materials \& Structures, 4(3), pp. 199-234. 